\title{
Impact of water activity on double layer parameters at the mercury/ chlorates(VII) interface in the presence of mixed adsorption layers of 6-mercaptopurine-Triton X-100
}

\author{
Agnieszka Nosal-Wiercińska ${ }^{1} \cdot$ Waldemar Kaliszczak $^{1} \cdot$ Anna Drapsa $^{1} \cdot$ Małgorzata Wiśniewska $^{2} \cdot$ Selehattin Yilmaz $^{3}$. \\ Sultan Yagmur ${ }^{4}$. Gulsen Saglikoglu ${ }^{3}$
}

Received: 10 January 2019 / Revised: 14 March 2019 / Accepted: 27 March 2019 / Published online: 4 April 2019

(c) The Author(s) 2019

\begin{abstract}
Adsorption mechanism of 6-mercaptopurine, 6-mercaptopurine-Triton X-100 on the mercury electrode surface from 2, 4 and to $6 \mathrm{~mol} \mathrm{dm}^{-3}$ chlorates(VII) was studied as the function of adsorbate bulk concentration. The experimental data obtained from the measurements of differential capacity of the double layer were used, namely the measurements of zero charge potential and surface tension at the zero charge potential. In the case of mixed adsorption layer of 6-mercaptopurine-Triton X-100 domination of 6MP in adsorption equilibria formation as well as competitive adsorption between the 6-mercaptopurine-Triton X-100 molecules were found. Significant contribution of water molecules in the adsorption-desorption processes was also observed.
\end{abstract}

Keywords Adsorption · Differential capacity · Triton X-100 · 6-Mercaptopurine · Water activity

\section{Introduction}

Water behaviour in different environments is an important factor in chemical systems. In biology water is found in cells where it hydrates membranes and large biomolecules. In geology interfacial water molecules can control ion adsorption and mineral dissolution. In chemistry water is

This article belongs to S.I. ISSHAC10, but it reach the press at the time the special issue was published.

Agnieszka Nosal-Wiercińska

anosal@poczta.umcs.lublin.pl

1 Faculty of Chemistry, Department of Analytical Chemistry and Instrumental Analysis, Maria Curie-Sklodowska University, M. Curie-Sklodowska Sq. 3, 20-031 Lublin, Poland

2 Faculty of Chemistry, Department of Radiochemistry and Colloids Chemistry, Maria Curie-Sklodowska University, M. Curie-Sklodowska Sq. 3, 20-031 Lublin, Poland

3 Faculty of Science and Arts, Department of Chemistry, Canakkale Onsekiz Mart University, Terzioglu Campus, 17020 Canakkale, Turkey

4 Lapseki Vocational School, Department of Chemistry and Chemical Processing Technology Programs, Program of Laboratory Technology, Canakkale Onsekiz Mart University, Lapseki, Canakkale, Turkey an important polar solvent that is often in contact with various interfaces, for example, in ion-exchange resin systems (Fayer 2012).

Due to commonness of metals application and increasing aggressiveness of the natural environment as a result of water and air pollution a special attention should be paid to the phenomenon of corrosion. It is subject of intensive investigations by scientists searching better and better as well as more effective preventive methods. One of the ways of its reduction is the use of corrosion inhibitors (Obot et al. 2014; Deng et al. 2014; Solmaz 2014). Effective action of these substances depends largely on their adsorption properties as well as kind of metal and environment. Owing to their great effectiveness, simplicity of production and relatively low price, ionic and non-ionic surfactants are effective inhibitors of steel, copper, aluminium, and iron corrosion (Fuchs-Godec and Žerjav 2009; El-Tabei and Hegazy 2013). Application of surfactants and other organic substances mixtures can improve significantly effectiveness of corrosion prevention (Fuchs-Godec 2007).

The study of organic compounds adsorption at the electrode/solution interface allows to describe the structure of the electrical double layer, the kinetics of electron transfer and the effect of metal corrosion inhibitors (Munoz et al. 1992; Nieszporek et al. 2012; Nosal-Wiercińska 2012, 2014, 2013; Nosal-Wiercińska and Dalmata 2010). 
A comprehensive analysis of the experimental data concerning adsorption of surface-active compounds on different solid metals seems to support the view that the mixed adsorption on the mercury surface should proceed analogously.

In the previous studies the competitive adsorption between the 6-mercaptopurine-Triton X-100 or mixed micelles were observed (Nosal-Wiercińska et al. 2018).

The influence of 6-mercaptopurine-Triton X-100 and water activity on the double layer parameters at the mercury/ chlorates(VII) interface is examined in the present paper.

The choice of water as the medium which affects the parameters of the double layer at the mercury/chlorates(VII) interface (Nosal-Wiercińska et al. 2018) was motivated by its specific properties and the fact that most chemical processes takes place in the aqueous environment. The measurements conducted in the solutions of different water activity [2, 4 and $6 \mathrm{~mol} \mathrm{dm}^{-3}$ chlorate(VII) corresponding with water activities: $0.927,0.832$ and 0.704 , respectively (Komorsky-Lovrič et al. 1993)] would allow to describe better both 6-mercaptopurine-Triton X-100 adsorption and the influence of the degree of electrode surface hydration on the adsorption-desorption processes.

\section{Experimental}

\subsection{Materials and methods}

The experiments were performed using a three-electrode cell with a hanging controlled growth mercury drop electrode (CGMDE) (Entech, Cracow, Poland) as the working electrode (electrode area was $0.009487 \mathrm{~cm}^{2}$, drop time was $3 \mathrm{~s}$ ), $\mathrm{Ag} / \mathrm{AgCl} /$ saturated $\mathrm{NaCl}$ as the reference electrode and a platinum spiral as the counter electrode (Scheme 1).

The measurements were made in thermostated cells at $298 \mathrm{~K}$ with the electrochemical analyzer $\mu$ Autolab/GPES

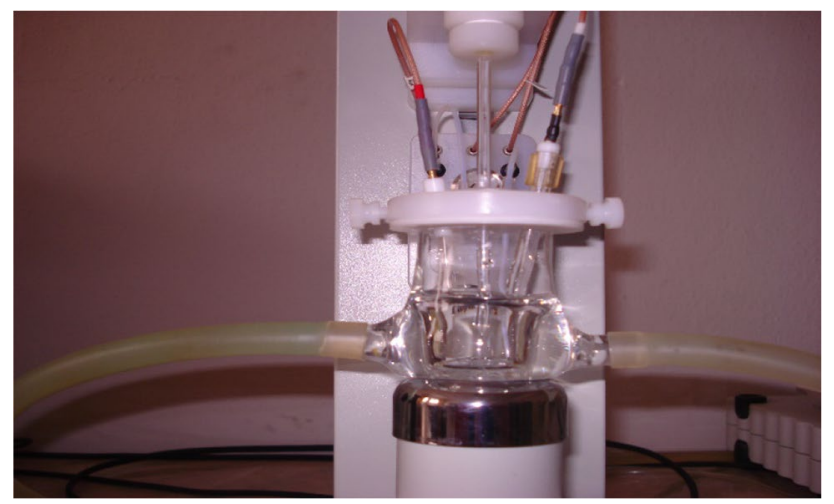

Scheme 1 Three-electrode cell
(Version 4.9) (Eco Chemie, Utrecht, the Netherlands) (Scheme 2).

The differential capacity of the double layer $\left(C_{d}\right)$ at the mercury/ supporting electrolyte interface was measured by the impedance method. The reproducibility of the differential capacitance measurements was $5 \%$. The potential of zero charge $\left(E_{z}\right)$ was determined using a streaming electrode. For the whole polarisation range, the capacity dispersion was tested at different frequencies changing in the range 200-1000 Hz. The occurrence of frequency dispersion was found for all examined systems. As a result of the differential capacitance extrapolation to zero frequency, the differential capacity curves corresponding to the adsorption equilibrium were obtained.

The surface tension at the potential of zero charge $\left(\gamma_{z}\right)$ was measured using the method of the highest pressure inside the mercury drop. Both $E_{\mathrm{z}}$ and $\gamma_{\mathrm{z}}$ were determined using a capillary electrometer (Scheme 3) (Nosal-Wiercińska 2012),

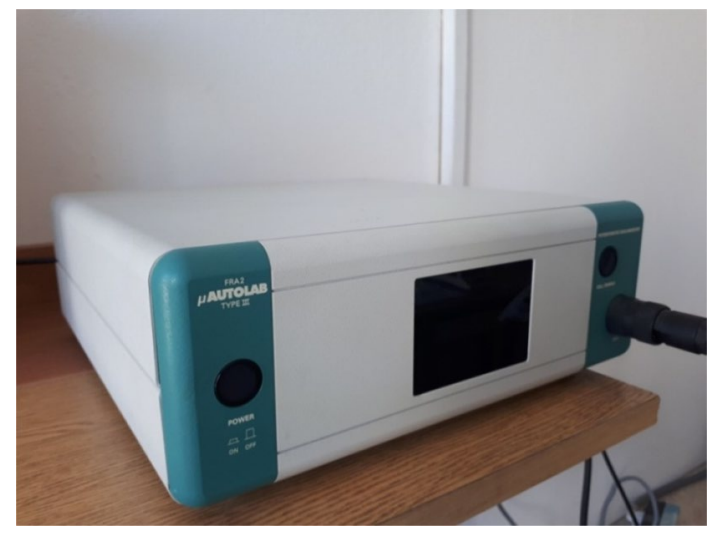

Scheme 2 Electrochemical analyzer $\mu$ Autolab

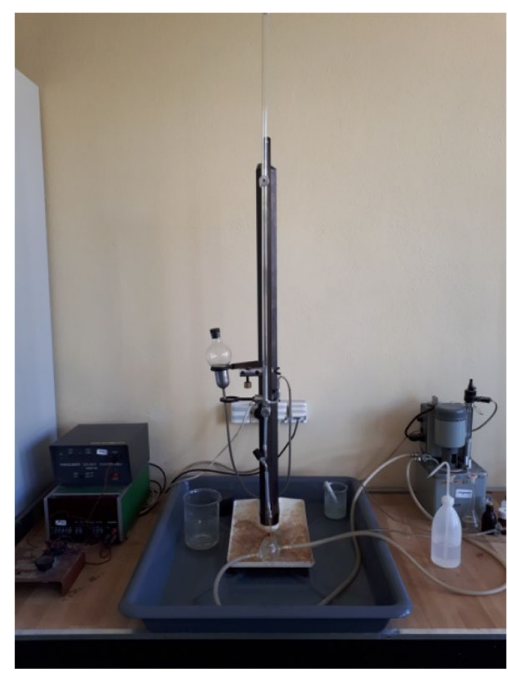

Scheme 3 Capillary electrometer 
with the accuracy respectively: $\pm 0.1 \mathrm{mV}$ for $E_{\mathrm{z}}$ and \pm 0.2 $\mathrm{mNm}^{-1}$ for $\gamma_{\mathrm{Z}}$.

Analytical-grade reagents: 6-mercaptopurine (Fluka), $\mathrm{NaClO}_{4}$ (Fluka) and $\mathrm{HClO}_{4}$ (Fluka), Triton X-100 (SigmaAldrich) were used without further purification. The solutions were prepared using doubly-distilled water. Before the measurements the solutions were deaerated using highpurity nitrogen. Nitrogen was passed over the solution during the measurements.

2, 4 and $6 \mathrm{~mol} \mathrm{dm}^{-3}$ chlorate(VII) solutions, mixed at proper ratios $\left[\mathrm{x} \mathrm{mol} \mathrm{dm}{ }^{-3} \mathrm{NaClO}_{4}+1 \mathrm{~mol} \mathrm{dm}^{-3} \mathrm{HClO}_{4}\right.$ (where $0 \leq x \leq 5$ )] were used as a basic electrolyte.

The solutions were prepared just before measurements. The concentrations of $6 \mathrm{MP}$ were in the range of $0.5-50 \times 10^{-3} \mathrm{~mol} \mathrm{dm}^{-3}$ whereas those of Triton X-100 were in the range $1 \times 10^{-6}-1 \times 10^{-3} \mathrm{~mol} \mathrm{dm}^{-3}$.

\section{Results and discussion}

The changes of adsorption parameters as a function of the supporting electrolyte concentration point out to the competitive adsorption in 6-mercaptopurine-Triton X-100 system as well as the electrostatic interactions between the adsorbate and the water molecules.

Figures 1, 2 and 3 show the capacitance curves in 2, 4, 6 mol dm ${ }^{-3}$ chlorates(VII) in the presence of 6-mercaptopurine. In the region of the "hump" potentials, appearing in chlorate(VII) without the studied substances $(\approx-200$ to $-800 \mathrm{mV}$ ) after the addition of 6-mercaptopurine, the height of the "hump" decreases. It should be pointed out that in the $4,6 \mathrm{~mol} \mathrm{dm}^{-3}$ chlorates(VII) this area of potentials is still broader being from -100 to $-1000 \mathrm{mV}$. The increase in the concentration of the studied substances causes a further decrease in differential capacitance in the region of "hump" potentials. Such picture of capacity curves indicates strong adsorption properties of 6-mercaptopurine. In the region of higher potentials $(\approx 200 \mathrm{mV})$ the adsorption peaks occur in the presence of 6-mercaptopurine (Figs. 1, 2, 3), however in the area of the most negative potentials (about-1000) $\mathrm{mV}$ the desorption peak appears. Both peaks increase with the increasing adsorbate concentration in the basic electrolyte solution.

However, it should be stressed that in the solutions of the basic electrolyte of the smallest water activity the desorption peak (especially for the high concentration of 6MP) is poorly defined. This indicates competitive electrostatic interactions between the $6 \mathrm{MP}$ molecules, $\mathrm{ClO}_{4}^{-}$ions and water dipoles. Undoubtedly, water molecules are the largest hindrance in the 6-mercaptopurine adsorption on the mercury surface. An increased concentration of chlorate(VII) ions characterized by great ability to destroy water structure seems to be very advantageous (Nosal-Wiercińska 2013).

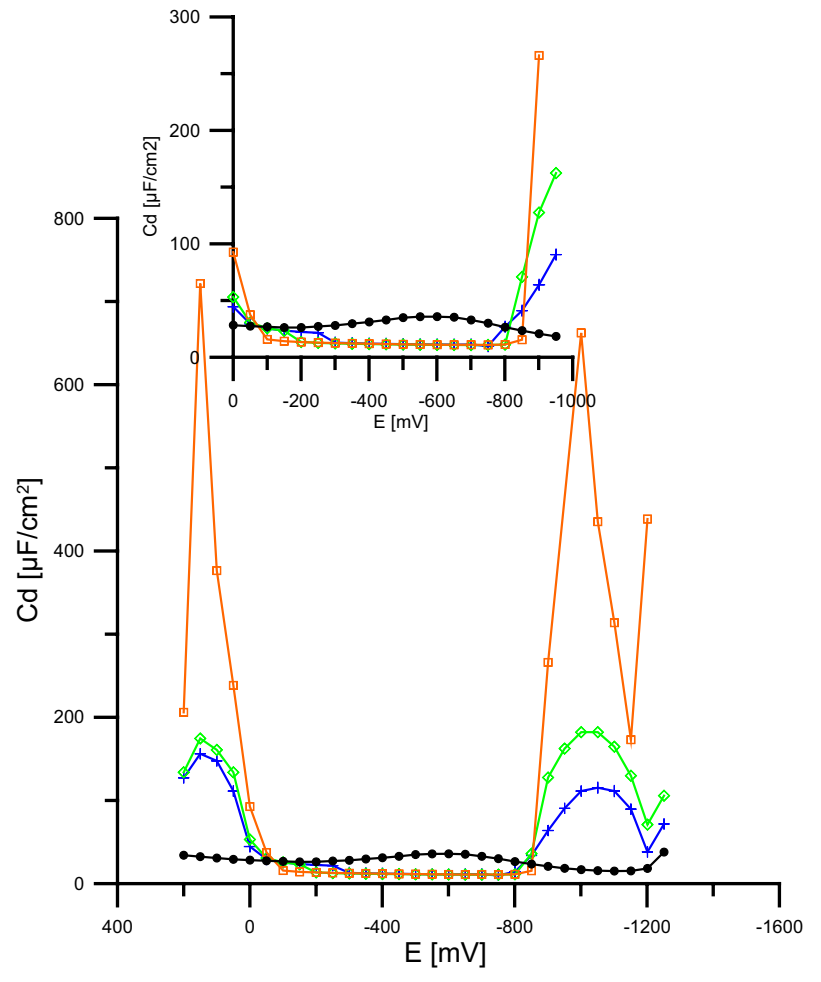

Fig. 1 Differential capacity-potential curves of double layer interface $\mathrm{Hg} / 2 \mathrm{~mol} \mathrm{dm}{ }^{-3}$ chlorate(VII) with various concentrations of 6-mercaptopurine: (closed circle) 0, 0,5 (cross), 1,0 (open diamond), 5,0 (open square) (in $\mathrm{mol} \mathrm{dm}^{-3}$ )

The earlier studies showed the specific adsorption of 6-mercaptopurine on the mercury surface (Nosal-Wiercińska et al. 2018).

Figures 4, 5 and 6 present the capacitance curves in $2,4,6 \mathrm{~mol} \mathrm{dm}^{-3}$ chlorates(VII) in the presence of $1 \cdot 10^{-3} \mathrm{~mol} \mathrm{dm}^{-3} 6$-mercaptopurine and the increasing Triton X-100 concentrations. The addition of the surfactant to the basic electrolyte solution containing mercaptopurine does not change the picture of capacity curves. This confirms distinct domination of 6MP in formation of adsorption equilibria of the mixed adsorption layers of 6MP-TritonX-100. It should be noticed that the increase in TritonX-100 concentration in the basic electrolyte results in the evident decrease of adsorption and desorption peaks. The desorption peaks even disappear which can be

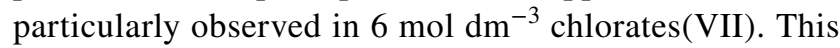
should be also associated with the effect of Triton X-100 on the adsorption equilibria formation (Wiśniewska et al. 2012). However, one should not exclude mutual interactions of 6MP and the surfactant molecules leading to the formation of a much less compact structure of adsorption layers. One should also mention about reduction of hydration degree of electrode surface due the increasing concentration of the basic electrolyte. This affects reorientation 


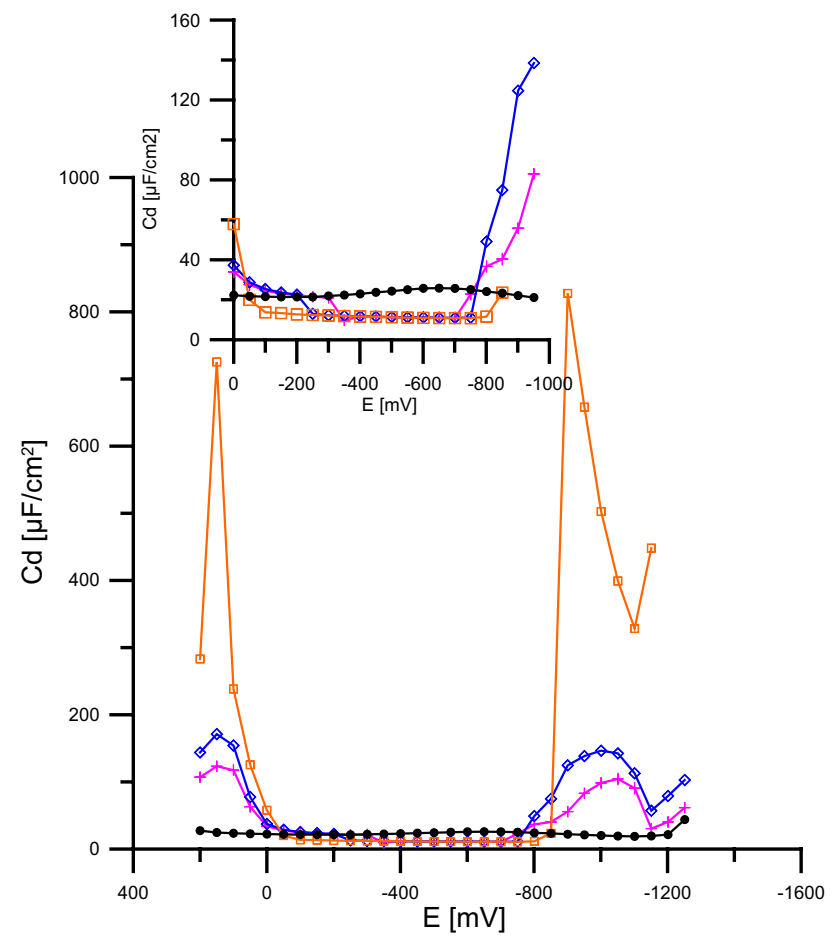

Fig. 2 Differential capacity-potential curves of double layer interface $\mathrm{Hg} / 4 \mathrm{~mol} \mathrm{dm}{ }^{-3}$ chlorate(VII) with various concentrations of 6-mercaptopurine: (closed circle) 0, 0,5 (cross), 1,0 (open diamond), 5,0 (open square)

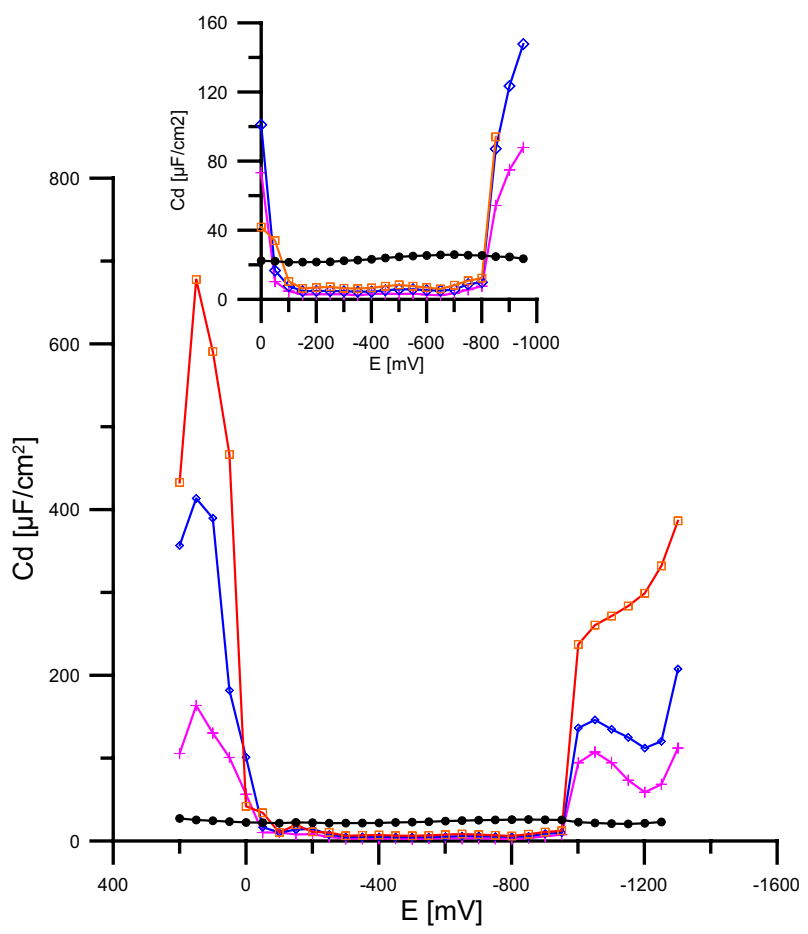

Fig. 3 Differential capacity-potential curves of double layer interface $\mathrm{Hg} / 6 \mathrm{~mol} \mathrm{dm}^{-3}$ chlorate(VII) with various concentrations of 6-mercaptopurine: (closed circle) 0, 0,5 (cross), 1,0 (open diamond), 5,0 (open square)

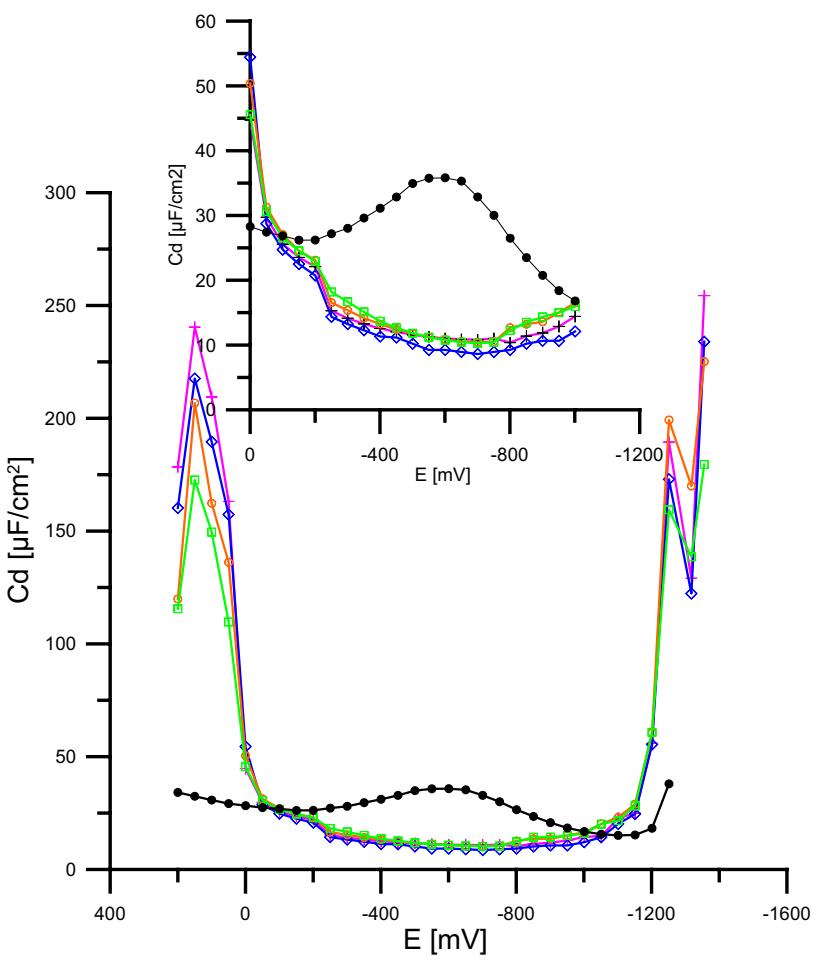

Fig. 4 Differential capacity-potential curves of double layer interface $\mathrm{Hg} / 2 \mathrm{~mol} \mathrm{dm}^{-3}$ chlorate(VII) with $1 \times 10^{-3} \mathrm{~mol} \mathrm{dm}^{-3}$ 6-mercaptopurine and with various concentrations of TritonX-100: (closed circle) 0, 1,0 (+), 4,0 (open diamond), 6,0 (open circle), 20 (open square) (in $\left.\mathrm{mol} \mathrm{dm}{ }^{-3}\right)$

of water molecules and changes the electrostatic interactions between the adsorbed molecules (Parsons and Reeves 1981).

Tables 1 and 2 present the values of the potentials of zero charge and those of the surface tension $\gamma_{z}$ at the zero charge potential for the studied systems. As follows from Table 1 the addition of 6-mercaptopurine to the 2, 4, $6 \mathrm{~mol} \mathrm{dm}$ chlorates(VII) solution causes shift of $E_{z}$ towards more negative potentials. This indicates that the adsorption of the 6-mercaptopurine dipoles proceeds via the sulfur atom oriented towards the mercury surface (Gugała-Fekner et al. 2009).

Moreover, with the increase in the 6-mercaptopurine concentration the $E_{z}$ values shift significantly towards evidently more negative potential values. Such changes of $E_{z}$ with the increasing concentration suggest change of $6 \mathrm{MP}$ molecules orientation on the mercury surface.

For the mixed adsorption layers of 6-mercaptopurine-Triton X-100 a similar behaviour is observed. However, the shifts of potentials are significantly smaller. This can be due to both 6MP and Triton X-100 molecules interactions leading to formation of a more or less compact structure of adsorption layers and the synergetic effect (Szymczyk and Jańczuk 2008). 


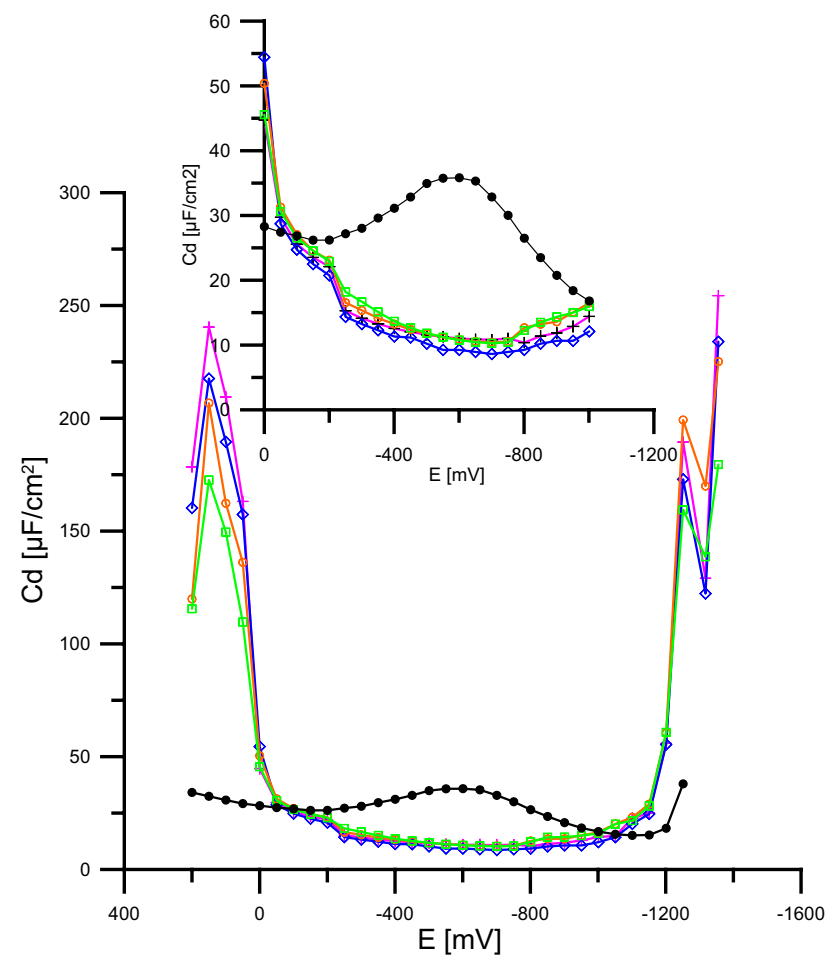

Fig. 5 Differential capacity-potential curves of double layer interface $\mathrm{Hg} / 4 \mathrm{~mol} \mathrm{dm}^{-3}$ chlorate(VII) with $1 \times 10^{-3} \mathrm{~mol} \mathrm{dm}^{-3}$ 6-mercaptopurine and with various concentrations of TritonX-100: (closed circle) 0, 1,0 (cross), 4,0 (open diamond), 6,0(open circle), 20 (open square) (in $\mathrm{mol} \mathrm{dm}^{-3}$ )

The values of surface tension $\gamma_{z}$ at the zero charge potential (Tables 1,2) decrease for all studied systems, as proved by the adsorption phenomenon (Nosal-Wiercińska 2013). The adsorption properties of both studied systems grow with the reduction in water activity. It should be noted that the reduction is slightly larger for the mixed adsorption layer compared to the system containing only 6MP.

\section{Conclusions}

It was proved that both 6-mercaptopurine, mixed adsorption layer of 6-mercaptopurine-Triton X-100 and activity of water have a significant effect on the parameters of the

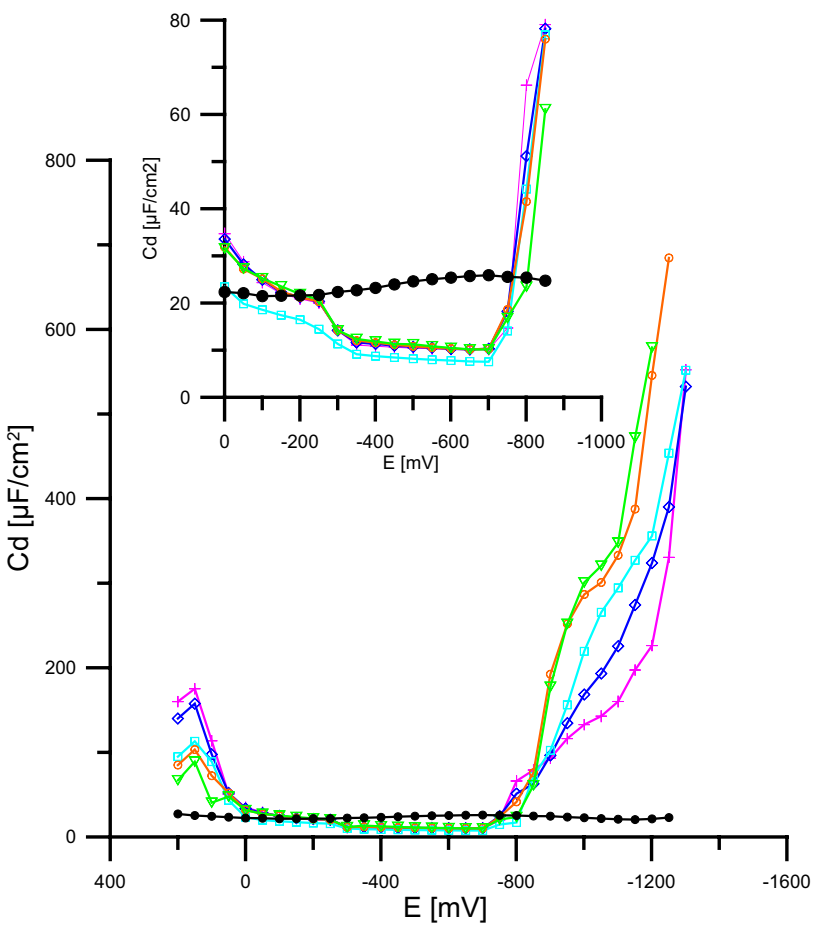

Fig. 6 Differential capacity-potential curves of double layer interface $\mathrm{Hg} / 6 \mathrm{~mol} \mathrm{dm}^{-3}$ chlorate(VII) with $1 \times 10^{-3} \mathrm{~mol} \mathrm{dm}^{-3}$ 6-mercaptopurine and with various concentrations of TritonX-100: (closed circle) $0,1,0$ (cross), 4,0 (open diamond), 6,0(open circle), 20 (open square) (in $\mathrm{mol} \mathrm{dm}^{-3}$ )

double layer at the $\mathrm{Hg} / \mathrm{chlorates}(\mathrm{VII})$ interface. The changes of adsorption parameters as a function of the supporting electrolyte concentration (with the water activity decrease: from 0.927 , through 0.832 to 0.704 ) point at competitive adsorption of 6-mercaptopurine and $\mathrm{ClO}_{4}^{-}$ions as well as electrostatic interactions between the adsorbate and the water molecules. In the case of the mixed adsorption layer of 6-mercaptopurine-Triton X-100, the dominance of 6MP in adsorption equilibria formation as well as the competitive adsorption between the 6MP and TritonX-100 molecules occur. Moreover, the formation of chemimicelles in $2 \mathrm{~mol} \mathrm{dm}^{-3}$ chlorates(VII) is also possible. 
Table 1 Potential of zerocharge $E_{z}$ versus $\mathrm{Ag}$ / $\mathrm{AgCl}$ electrode and surface tension $\gamma_{z}$ for $E_{z}$ of 2, 4 and $6 \mathrm{~mol} \mathrm{dm}^{-3}$ chlorates(VII) solutions + different 6-mercaptopurine systems

\begin{tabular}{|c|c|c|c|c|c|c|}
\hline \multirow[t]{2}{*}{$\begin{array}{l}10^{3} \mathrm{c}_{6 \mathrm{MP}} / \\
\mathrm{mol} \mathrm{dm}^{-3}\end{array}$} & \multicolumn{2}{|c|}{$2 \mathrm{~mol} \mathrm{dm}^{-3}$ chlorates(VII) } & \multicolumn{2}{|c|}{$4 \mathrm{~mol} \mathrm{dm}^{-3}$ chlorates(VII) } & \multicolumn{2}{|c|}{$\begin{array}{l}6 \mathrm{~mol} \mathrm{dm}^{-3} \\
\text { chlorates(VII) }\end{array}$} \\
\hline & $-E_{z} / V$ & $\gamma_{z} / \mathrm{mN} \mathrm{m}^{-1}$ & $-E_{z} / V$ & $\gamma_{z} / \mathrm{mN} \mathrm{m}^{-1}$ & $-E_{z} / V$ & $\gamma_{z} / \mathrm{mN} \mathrm{m}^{-1}$ \\
\hline 0 & 0.483 & 477.5 & 0.497 & 469.5 & 0.528 & 471.2 \\
\hline 0.5 & 0.489 & 426.7 & 0.508 & 419.1 & 0.540 & 418.2 \\
\hline 1.0 & 0.463 & 414.8 & 0.500 & 411.4 & 0.510 & 408.9 \\
\hline 5.0 & 0.430 & 407.2 & 0.479 & 400.2 & 0.476 & 401.1 \\
\hline
\end{tabular}

Table 2 Potential of zero-charge $E_{z}$ versus $\mathrm{Ag} / \mathrm{AgCl}$ electrode and surface tension $\gamma_{z}$ for $E_{z}$ of 2, 4, $6 \mathrm{~mol} \mathrm{dm}^{-3}$ chlorates(VII) solutions $+3 \times 10^{-5} \mathrm{~mol} \mathrm{dm}^{-3}$ TritonX-100+different 6-mercaptopurine concentration systems

\begin{tabular}{|c|c|c|c|c|c|c|}
\hline \multirow[t]{2}{*}{$\begin{array}{l}3 \times 10^{-5} \mathrm{~mol} \mathrm{dm}^{-3} \text { TritonX } \\
-100+10^{3} \mathrm{c}_{6 \mathrm{MP}} / \mathrm{mol} \mathrm{dm}^{-3}\end{array}$} & \multicolumn{2}{|c|}{$\begin{array}{l}2 \mathrm{~mol} \mathrm{dm}^{-3} \\
\text { chlorates(VII) }\end{array}$} & \multicolumn{2}{|c|}{$\begin{array}{l}4 \mathrm{~mol} \mathrm{dm}^{-3} \\
\text { chlorates(VII) }\end{array}$} & \multicolumn{2}{|c|}{$\begin{array}{l}6 \mathrm{~mol} \mathrm{dm}^{-3} \\
\text { chlorates(VII) }\end{array}$} \\
\hline & $-E_{z} / V$ & $\gamma_{z} / \mathrm{mN} \mathrm{m}^{-1}$ & $-E_{z} / V$ & $\gamma_{z} / \mathrm{mN} \mathrm{m}^{-1}$ & $-E_{z} / V$ & $\gamma_{z} / \mathrm{mN} \mathrm{m}^{-1}$ \\
\hline 0 & 0.483 & 477.5 & 0.497 & 469.5 & 0.528 & 471.2 \\
\hline 0.5 & 0.500 & 418.2 & 0.509 & 419.0 & 0.547 & 417.4 \\
\hline 1.0 & 0.472 & 412.3 & 0.499 & 410.0 & 0.513 & 408.3 \\
\hline 5.0 & 0.451 & 405.5 & 0.463 & 399.1 & 0.499 & 395.0 \\
\hline
\end{tabular}

Open Access This article is distributed under the terms of the Creative Commons Attribution 4.0 International License (http://creativeco mmons.org/licenses/by/4.0/), which permits unrestricted use, distribution, and reproduction in any medium, provided you give appropriate credit to the original author(s) and the source, provide a link to the Creative Commons license, and indicate if changes were made.

\section{References}

Deng, S., Li, X., Xie, X.: Hydroxymethyl urea and 1,3-bis(hydroxymethyl) urea as corrosion inhibitors for steel in $\mathrm{HCl}$ solution. Corros. Sci. 80, 276-289 (2014)

El-Tabei, A.S., Hegazy, M.A.: A corrosion inhibition study of a novel synthesized gemini nonionic surfactant for carbon steel in $1 \mathrm{M}$ $\mathrm{HCl}$ solution. J. Surfactant Deterg. 16, 757-766 (2013)

Fayer, M.D.: Dynamics of water interacting with interfaces, molecules, and ions. Acc. Chem. Res. 45, 3-14 (2012)

Fuchs-Godec, R.: Inhibitory effect of non-ionic surfactants of the TRITON-X series on the corrosion of carbon steel in sulphuric acid. Electrochim. Acta 52, 4974-4981 (2007)

Fuchs-Godec, R., Žerjav, G.: Inhibition properties of Triton-X-100 on ferritic stainless steel in sulphuric acid, at increasing temperature. Acta Chim. Slov. 56, 78-85 (2009)

Gugała-Fekner, D., Sieńko, D., Nieszporek, J., Klin, M., Saba, J.: Mixed adsorption layers of $0.1 \mathrm{M}$ tert-butanol-tetramethylthiourea at the interface of $\mathrm{Hg}$ /aqueous perchlorate solutions. J. Colloid Interface Sci. 332, 291-297 (2009)

Komorsky-Lovrič, S., Lovrič, M., Branica, M.: J. Electrochem. Soc. 140, 1850-1853 (1993)

Munoz, E., Rodriguez-Amaro, R., Ruiz, J.J., Avila, J.L., Camacho, L.: Inhibition of the electrode reduction of an adsorbed species by the competitive adsorption of surfactant. Study of the cefazolin-triton $\mathrm{X}-100$ system at the $\mathrm{Hg}-\mathrm{H}_{2} \mathrm{O}$ interface. J. Electroanal. Chem. 324, 359-374 (1992)

Nieszporek, J., Sieńko, D., Gugała-Fekner, D., Klin, M.: Properties of the mixed adsorption layer: neutral detergent-tetramethylthiourea at interface electrode/solution. Turk. J. Chem. 36, 841-851 (2012)
Nosal-Wiercińska, A.: Adsorption of cystine at mercury/aqueous solution of chlorate (VII) interface in solutions of different water activity. Cent. Eur. J. Chem. 10, 1290-1300 (2012)

Nosal-Wiercińska, A.: The influence of water activity on double layer parameters on the interface mercury/chlorates (VII) in the presence of cysteine. Croat. Chem. Acta 86, 159-164 (2013)

Nosal-Wiercińska, A.: Intermolecular interactions in systems containing $\mathrm{Bi}(\mathrm{III})-\mathrm{ClO}_{4}{ }^{-}-\mathrm{H}_{2} \mathrm{O}$-selected amino acids in the aspect of catalysis of $\mathrm{Bi}(\mathrm{III})$ electroreduction. Electroanalysis 26, 10131023 (2014)

Nosal-Wiercińska, A., Dalmata, G.: Adsorption of methonine at mercury/aqueous solution of chlorate(VII) interface; dependence on the supporting electrolyte concentration. Electroanalysis 22, 2081-2086 (2010)

Nosal-Wiercińska, A., Kaliszczak, W., Grochowski, M., Wiśniewska, M., Klepka, T.: Effects of mixed adsorption layers of 6-mercaptopurine-Triton X-100 and 6-mercaptopurine-Tween 80 on the double layer parameters at the mercury/chlorates(VII) interface. J. Mol. Liq. 253, 143-148 (2018)

Obot, I.B., Gasem, Z.M., Umoren, S.A.: Molecular level understanding of the mechanism of aloes leaves extract inhibition of low carbon steel corrosion: a DFT approach. Int. J. Electrochem. Sci. 9, 510-522 (2014)

Parsons, R., Reeves, R.M.: Molecular models for the structure of solvent in an interphase. J. Electroanal. Chem. 123, 141-149 (1981)

Solmaz, R.: Investigation of corrosion inhibition mechanism and stability of Vitamin B1 on mild steel in $0.5 \mathrm{M} \mathrm{HCl}$ solution. Corros. Sci. 81, 75-84 (2014)

Szymczyk, K., Jańczuk, B.: Wettability of a glass surface in the presence of two nonionic surfactant mixtures. Langmuir 24, 77557760 (2008)

Wiśniewska, M., Chibowski, S., Urban, T.: Effect of the type of polymer functional groups on the structure of its film formed on the alumina surface - suspension stability. React. Funct. Polym. 72, 791-798 (2012)

Publisher's Note Springer Nature remains neutral with regard to jurisdictional claims in published maps and institutional affiliations. 